\title{
Correction to: In vivo performance of a novel silk fibroin scaffold for partial meniscal replacement in a sheep model
}

\author{
Katharina Gruchenberg ${ }^{1} \cdot$ Anita Ignatius $^{1} \cdot$ Benedikt Friemert ${ }^{2} \cdot$ Falk von Lübken $^{2} \cdot$ Nick Skaer $^{3} \cdot$ Kris Gellynck $^{4}$. \\ Oliver Kessler $^{5} \cdot$ Lutz Dürselen $^{1}$
}

Published online: 26 February 2018

(c) European Society of Sports Traumatology, Knee Surgery, Arthroscopy (ESSKA) 2018

\section{Correction to:}

\section{Knee Surg Sports Traumatol Arthrosc}

(2015) 23:2218-2229

https://doi.org/10.1007/s00167-014-3009-2

The author would like to correct the errors in the publication of the original article. The corrected details are given below for your reading.
The original article can be found online at https://doi.org/10.1007/ s00167-014-3009-2.

Lutz Dürselen

lutz.duerselen@uni-ulm.de

Institute of Orthopaedic Research and Biomechanics, Centre of Musculoskeletal Research, University of Ulm, Helmholtzstraße 14, 89081 Ulm, Germany

2 Department of Trauma and Orthopaedic Surgery, Centre of Musculoskeletal Research, Hospital of the Federal Armed Forces Ulm, 89081 Ulm, Germany

3 Orthox Ltd., Abingdon OX14 3HG, UK

4 Division of Biomaterials and Tissue Engineering, Eastman Dental Institute, University College London, London WC1X 8LD, UK

5 Centre for Orthopaedic and Sports Medicine, 8047 Zurich, Switzerland
The Fig. 4 should be:

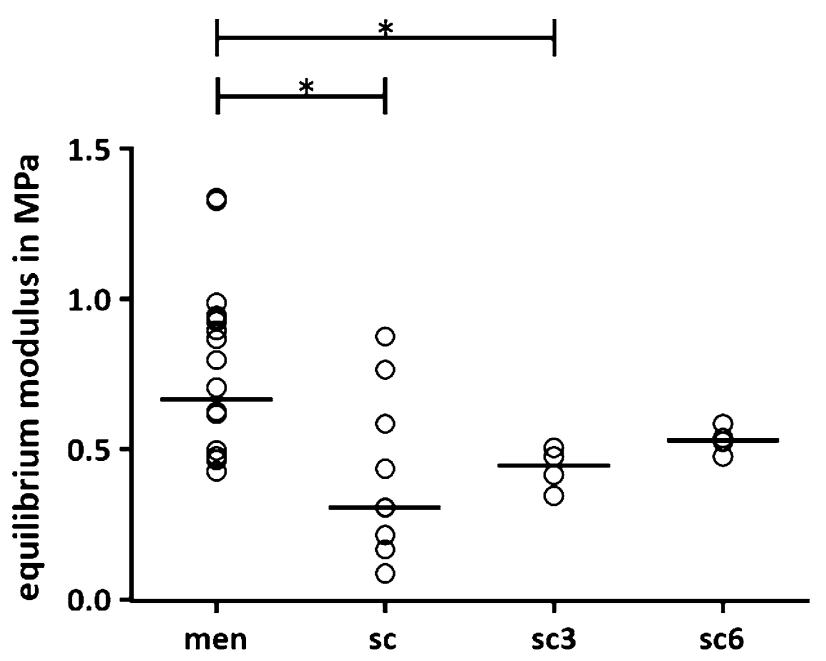

In page 2223, under the "Stress-relaxation test of meniscus and scaffold" section, the third sentence should read as:

"However, the equilibrium modulus of the scaffolds implanted in the stifle joint increased over the implantation period, and after 6 months of implantation, there was no longer a significant difference between the meniscal tissue $(0.67 \mathrm{MPa})$ and the scaffold $(0.53 \mathrm{MPa}) "$. 